\title{
Emergency Repair of Xushui River Bridge in the Expressway around Zhengzhou
}

\author{
Jianlong ZHANG \\ Henan Provincial Department of Transportation Highway \\ Administration Bureau \\ Chang'an University \\ Xi'an, China \\ e-mail: 404631782@qq.com
}

\section{Pinde YU}

Henan Transportation Research Institute CO., LTD

Highway Bridge Safety Inspection and Reinforcement

Technology Transportation Industry Research and

$$
\begin{aligned}
& \text { Development Center } \\
& \text { Zhengzhou, China } \\
& \text { e-mail: ypd@hntri.com }
\end{aligned}
$$

\author{
Kun CHENG \\ Henan Transportation Research Institute CO., LTD \\ Highway Bridge Safety Inspection and Reinforcement \\ Technology Transportation Industry Research and \\ Development Center \\ Zhengzhou, China \\ e-mail: ck@hntri.com
}

\begin{abstract}
An safety accident of Xushui River bridge in the southwest expressway around Zhengzhou city occurred in July 2014. Due to the accumulation of building waste materials near the bridge, one of pier columns was broken up by accidental horizontal load. Key technology for emergency repair construction of the bridge was concerned in this paper. Firstly, the repair plan and difficulty was carried out. Then the main construction steps were described in detail. In the end, main characteristics of the emergency project were summarized based on the whole repair process.
\end{abstract}

Keywords-expressway; bridge; emergency repair;
construction

\section{INTRODUCTION}

Over the past few years, a number of bridge safety incidents have occurred, such as the pier failure accident of a viaduct crossing Beijing-Zhuhai expressway crashed by a large truck in 2009, the collapse accident of Yichang bridge in Lianhuo expressway caused by vehicle explosion in 2013, and the fire accident of Yellow River bridge in Beijing-Hong Kong- Macao expressway in 2016. Any bridge safety incident, whether it is bridge damage caused by fire, vehicle impact and overload, or bridge collapse caused by earthquake and flood, will bring serious economic loss and adverse social impact.

Different from other related researches on bridge emergency [1-5], this paper mainly concerns emergency repair of Xushui River Bridge in the expressway around Zhengzhou city. Firstly, the repair plan and difficulty was carried out. Then the main construction steps were described in detail. In the end, main characteristics of the emergency project were summarized based on the whole repair process.

\section{Qing LI}

Henan Province Highway Engineering Bureau Group Co., Ltd

Zhengzhou, China

e-mail:532568952@qq.com

\section{PROJECT OVERIEW}

Xushui River Bridge is located in the southwest expressway around Zhengzhou city. The bridge is $226.88 \mathrm{~m}$ in length and $2 \times 16.5 \mathrm{~m}$ in width, with a span arrangement of $5 \times 20+6 \times 20 \mathrm{~m}$. The superstructure of the bridge is prefabricated prestressed concrete continuous small box girder, the substructure is pile-type structure, the length of piles is $38 \mathrm{~m}$, the highest pier column is $13.5 \mathrm{~m}$, and the diameters for piles and piers are $1.5 \mathrm{~m}$ and $1.2 \mathrm{~m}$, respectively. Fig. 1 and Fig.2 give the elevation and cross section of Xushui River Bridge.

As shown in Fig.3, the bridge safety accident was unfortunately occurred in July 7, 2014. A large number of building waste materials were deliberately dumped on the west side of the bridge, and the vertical height of the waste was $5 \mathrm{~m}$ higher than the bridge deck. Along with the accumulation of building waste materials, one of the pier columns of the bridge (No.p6-1\#) was obviously inclined and cracked (Fig.3). Without supporting, the main girders had large vertical deflection, which seriously affected the traffic safety. The observation results showed that the cap beam, the middle pier (No.p6-2\#) and several main girders were damaged, and the bearing cavity also appeared.

\section{BRIDGE REPAIR PLAN AND DIFFICULTY ANALYSIS}

\section{A. Emergency Repair Plan}

In order to shorten the repair construction period and guarantee the construction safety, a repair construction plan was firstly determined. 


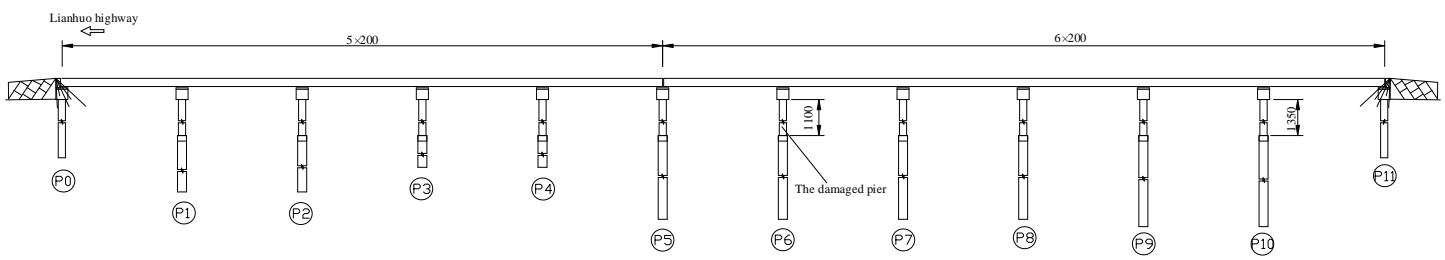

Figure 1. Layout of Xushui River bridge (unit: $\mathrm{cm}$ )

As shown in Fig.4, the main process of the repair construction plan can be described as: (a) clear the building waste; (b) stable the damaged pier column and cap beam using temporary support; (c) remove the silt under the bridge; (d) temporarily support the superstructure; (e) remove the damaged substructure and rebuild the substructure; (f) clear all temporary structures and finish the repair construction.

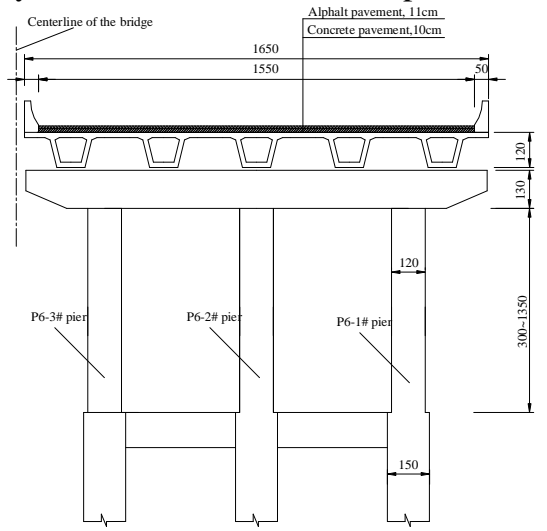

Figure 2. Cross section of Xushui River bridge (unit: $\mathrm{cm}$ )

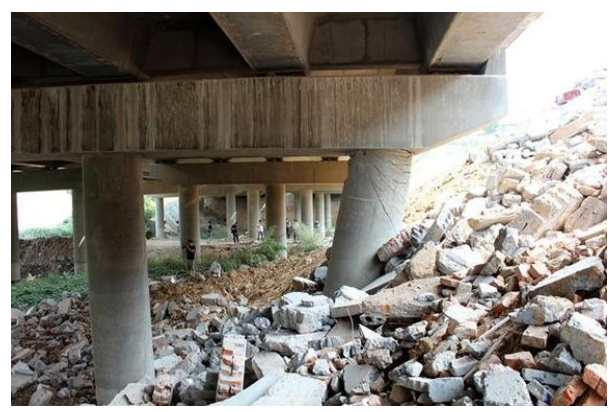

Figure 3. Accident photo

\section{B. Repair Difficulty Analysis}

Based on the actual condition of the bridge, the following key points and difficulties in the whole repair process were considered.

(1) The damaged p6-1\# pier was located in the lowest area of the river. The detection result indicated that there was a lot of silt under the bridge, and the depth of the silt was about $5-7 \mathrm{~m}$. Therefore, the work of removing the silt would be the first difficulty in the whole repair period.

(2) The p6-1\# pier had been totally failed, and the substructure nearby was also damaged. That is to say, the superstructure was almost unstable and had a high safety risk. How to make sure the safety of workers and machinery under the bridge was another key point.
(3) The accident just occurred in the rainy season. Therefore, the drainage work was also one of the most important facilities to guarantee the smooth progress of the repair construction.

(4) The maximum height of the bridge pier is about $13 \mathrm{~m}$, which cannot completely satisfy the normal construction space for removing the damaged substructure and rebuilding new substructure. The repair construction under the bridge would be very difficult.

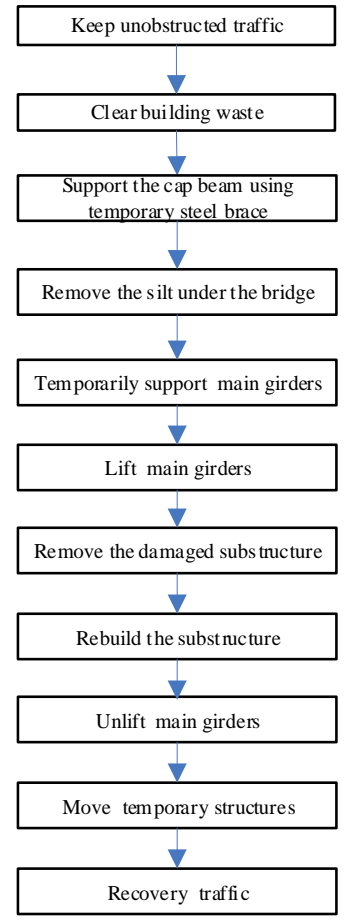

Figure 4. Flowchart for emergency repair

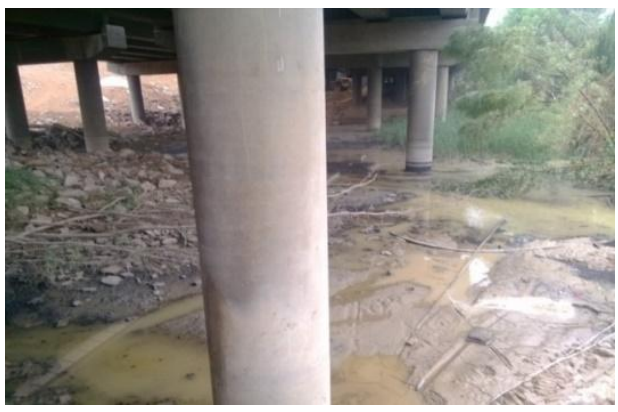

Figure 5. Original silt situation under the bridge 


\section{EMERGENCY REPAIR CONSTRUCTION}

\section{A. Unload and Cap Beam Temporary Support}

The first step of the emergency repair construction was to clear the building waste materials and unload the horizontal soil pressure. But it was noted that the unloading speed should be strictly controlled, and the whole unloading process must be real-time monitored to ensure the stability of the damaged structure.

The p6-1\# pier had been broken up which caused the cap beam was nearly under cantilever state. In order to ensure the stability of superstructure and construction safety under the bridge, the damaged cap beam was immediately supported using a steel brace after clearing the building waste materials. As shown in Fig.6, the steel support was arranged on the side of the bridge, and bored piles were used as the foundation of the steel inclined brace.

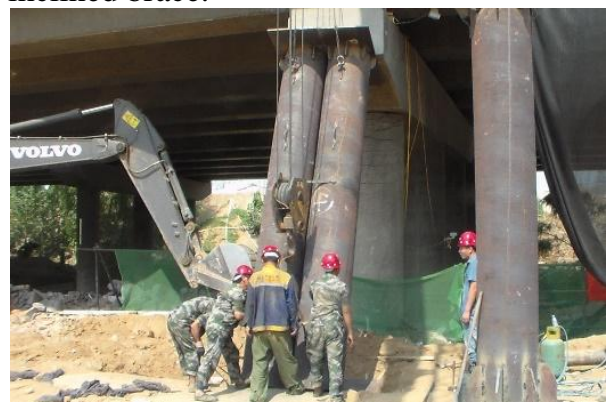

Figure 6. Installing temporary support of the cap beam

\section{B. Silt Cleaning}

This construction procedure should be carried out after the temporary support of the cap beam was completed. Key points for silt cleaning mainly included:

(1) Mixed excavation. While the silt excavation construction was going on, soil should also be mixed to the silt to reduce silt mobility and ensure excavation efficiency.

(2) Double-line excavation. As shown in Fig. 7, to speed up the construction progress, double-line excavation method was adopted.

(3) Soil replacement. This part mainly takes into consideration the mobility of silt. After cleaning the silt, new soil was immediately back filled. But it should be noted that the replaced soil was different from the mixed soil in the process of excavation.

(4) Site determination of excavation depth. Due to the complexity of the field condition, the excavation depth was site determined. The work should be continued until excavating to the hard ground.

\section{Main Girder Temporary Support}

Five steel pipe columns were selected as the main girder temporary support, and the foundation was an expanded concrete foundation. Main process for this temporary support system was as follows:

(1) Paving cushion of the expanded foundation. The cushion used gravel cushion and concrete cushion with thickness of $90 \mathrm{~cm}$ and $20 \mathrm{~cm}$, respectively.

(2) Casting concrete of the expanded foundation.
(3) Installing temporary steel column. Here, the seamless steel pipe with $14 \mathrm{~mm}$ thickness of $14 \mathrm{~mm}$ and diameter of $630 \mathrm{~mm}$. was used. Due to the limited space under the bridge, every column was sectional lifted and bolt connected. Meanwhile, these temporary columns were welded connected to each other using horizontal steel braces to make sure the overall stability.

(4) Installing transversal beam and supporting main girders. Two 63C I-beams were welded together and lifted to the top of the temporary columns as a transversal beam. Finally, the jacks were placed on the transversal beam and synchronous lifted the main girders. It was required that the number and position of the jacks should corresponded to the original rubber bearings of the bridge for the purpose of protecting the main girder.

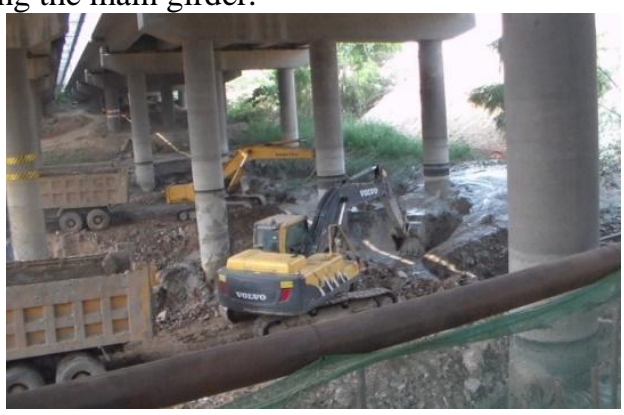

Figure 7. Double-line cleaning silt

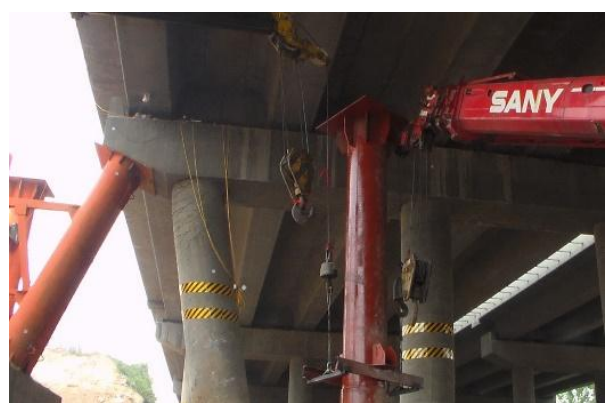

Figure 8. Lifting temporary support of main girders

\section{Damaged Structures Removal}

While the main girders were temporary lifted using jacks, the damaged cap beam and columns were gradually removed.

1) Cap beam removal:

As shown in Fig.9, taking into account the lifting space and construction space were limited; the cap beam was artificially chiseled up using air compressors.

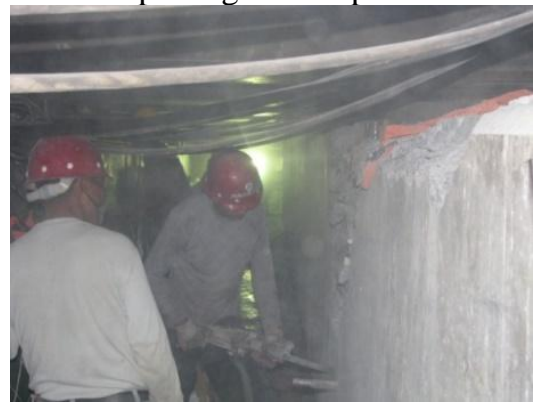

Figure 9. Artificially chiseling the cap beam 


\section{2) Pier column removal:}

In the construction of the pier columns, a hoop bracing plan was considered. As indicated in Fig. 10, three hoops were installed in every column, and these hoops were connected with each other using lateral and inclined steel braces.

In the process of removing damaged columns from top to bottom, the corresponding hoops were also one by one moved out until the removal construction was completed. Fig. 11 shows the site photo of removal of the columns.

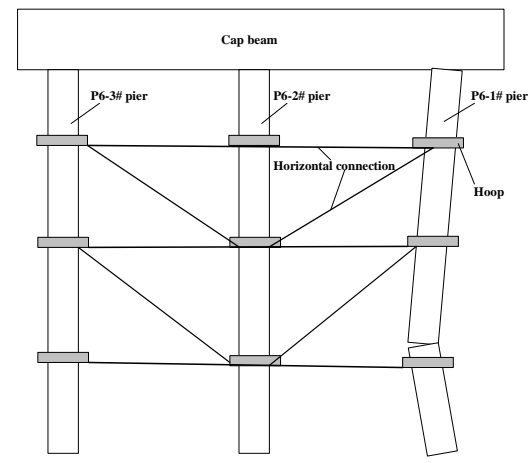

Figure 10. Schematic diagram of horizontal connection for column

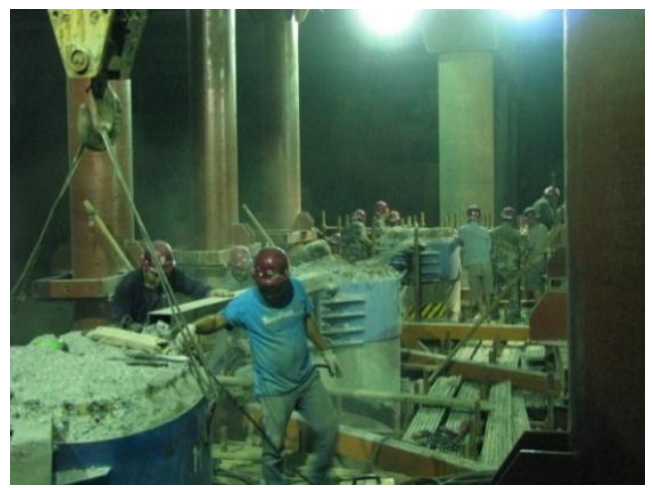

Figure 11. Chiseling damaged piers

\section{E. New Columns and Cap Beam Construction}

The difficulty for construction of the new columns and cap beam mainly reflected in the narrow construction space. The reinforcements of new structures must be artificially carried to the site, and concrete vibrator also must be artificially operated in the template. Another difficulty was the construction of bearing pad stone, which can be seen in Fig.12. All concrete casting was done manually.

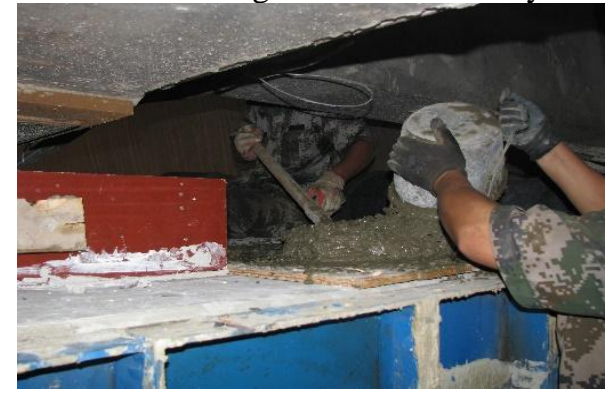

Figure 12. Casting concrete of bearing pad stone

\section{F. System Conversion}

The last step of this emergency repair was system conversion. When new bearings were completed placed and the concrete of new columns and cap beam reached the design strength, all jacks synchronous fall back, and the system conversion was completed.

\section{PROJECT CHARACTERISTICS ANALYSIS}

Although the accident bridge is located in the Central Plains area, the project of emergency repair has its own characteristics.

\section{1) Complicated site situation:}

Through the site investigation, the failed pier was located in the low-lying place, and the thickness of silt layer under the bridge was as deep as $5-7 \mathrm{~m}$. The amount of the building waste was large, which made the difficulty of unloading was high. However, the most important points were that the superstructure of the bridge was unstable, and the whole emergency repair period was in rainy season. All of these complicated situations made the emergency repair construction extremely difficult.

\section{2) High construction risk:}

Due to the damage of the substructure, the mechanical characteristics of the bridge had obviously changed. The main girder near bearings was under positive bending moment after the failure of the pier columns. Therefore, the whole superstructure of the bridge was unstable. Any slight disturbance by any aspect of the emergency repair construction was likely to bring unexpected secondary disaster.

Taking the unloading of building waste for instance, the damaged pier would rebound after unload the lateral pressure caused by building waste. High construction risk existed for both construction machinery and personnel.

3) Difficult repair construction and strict construction period requirement:

In the whole repair construction process, from the beginning of the temporary support construction of cap beam, to the final bearing pad stone concrete casting, the difficulty of small construction space always existed. On the other hand, bridge emergency repair is obviously different from conventional construction. The repair period requirement is very strict under the premise of ensuring construction quality, always accompanied by simultaneously carry out of design and construction, and 24-hour uninterrupted construction.

\section{CONCLUSION}

This paper discussed the emergency repair case of Xushui River Bridge in the southwest expressway around Zhengzhou city. The repair plan and difficulty was firstly carried out, the main construction steps were described in detail, and the characteristics of the emergency project were finally summarized. The presented repair case can provide reference for similar emergency projects.

\section{REFERENCES}

[1] LU Xin-zheng, ZHANG Yan-sheng, HE Shui-tao, LU Xiao. Collision between over-high trucks and bridge superstructures: damage 
mechanism and impact loads [J]. Engineering Mechanics, 2009, 12(26, S2): $115-125$

[2] Wei Wang, Ruichao Liu, Biao Wu. Analysis of a bridge collapsed by an accidental blast loads [J]. Engineering Failure Analysis, 2014, 36: 353-361.

[3] Maria Garlock, Ignacio Paya-Zaforteza, Venkatesh Kodur, et al. Fire hazard in bridges: Review, assessment and repair strategies [J]. Engineering Structures, 2012, 35:89-98
[4] PEI Xiao-yin, WEN Chuan-yong, ZHANG Yong-shui. Analysis on Damage of Urban Bridges Caused by Vehicle Collision [J]. Journal of Chongqing Jiaotong University (Natural Science), 2011, 01:19$21+106$.

[5] Huang Qing. Inspection and Evaluation of Reinforced Concete Bridges after Fire Disaster [J]. World Bridge, 2014, 05: 78-82. 